\title{
A condução da negociação da face em um livro didático de língua estrangeira e seus desdobramentos na sala de aula
}

\section{Maria do Carmo Milito Gama \\ Professora do Centro Federal de Educação \\ Tecnológica de Alagoas - CEFET-AL e doutoranda pelo Programa de Pós-Graduação em Letras e Linguística da Faculdade de Letras da UFAL. Seus temas de interesse sāo: negociaçāo da face, ensino de lingua inglesa, inglês para fins específicos.}

Resumo: Neste artigo, apresentamos uma análise das ocorrências de estratégias de negociação da face no texto de uma unidade de um livro didático de inglês para o segundo grau, partindo do pressuposto de que, neste contexto, a face dos interlocutores pode estar por natureza ameaçada, devido à imposiçāo com que se dá sua leitura. A partir dessa análise, refletimos sobre possiveis analogias entre a unidade do livro e uma unidade de aula em uma abordagem comunicativa.
Abstract: In this article I present an analysis of the face-saving strategies occurences in a lesson of an English didactic book for high-school level, assuming that in this context the interlocutors' lace may be threatened by nature due to the imposition of their reading. From this analysis I consider the possibility of analogies between the lesson analysed and a class unit based on a comunicative approach.
Palavras-chave: interação em sala de aula; negociaçäo da face; abordagem comunicativa; livro didático
Keywords: classroom interaction; face-saving; communicative approach; didactic book 



\section{Introdução}

Os estudos sobre a interação em sala de aula têm despertado o meu interesse já há algum tempo, e dentre os diversos elementos observáveis nesse contexto, direcionei mais objetivamente minha atenção para as estratégias discursivas de negociação da face (GOFFMAN, 1967; BROWN \& LEVINSON, 1987; TAVARES, 2001).

Em trabalhos realizados anteriormente, analisei a ocorrência das estratégias de negociação da face sempre no discurso oral dos interlocutores. Em um primeiro momento, focalizei a sala de aula de língua estrangeira (GAMA, 1996), seguindo os princípios de uma abordagem comunicativa (WIDDOWSON, 1991; ALMEIDA FILHO, 1993); e em um segundo momento de pesquisa, direcionei meus estudos para um outro contexto, o das entrevistas jornalísticas de televisão (GAMA, 1999). Em leituras posteriores sobre o mesmo tema, compreendi, através de Maingueneau $^{1}$ (2002), que essas estratégias encontramse também em textos escritos, pois, considerando que textos escritos também configuram uma relação social, eles submetem-se, da mesma forma que o discurso oral, às regras da polidez. Um exemplo é dado por este mesmo autor, que analisa a ocorrência de elementos da polidez em um texto de publicidade escrito, justificando essa análise com a afirmação de que no discurso publicitário o problema da negociação das faces é primordial porque sua enunciação é por natureza ameaçada. O autor justifica esta afirmação:

O simples fato de pedir para ser lido constitui ao mesmo tempo uma ameaça para a face positiva do responsável pela enunciação, a marca do produto (que pode ser vista como uma "chatice") e uma ameaça para as faces negativa e positiva do destinatário (tratado como alguém sem importância, a quem se pode pedir que dedique uma parte do seu tempo à leitura do enunciado publicitário). (MAINGUENEAU, 2002, p. 40)
'Trago Dominique Maingueneau, que segue a linha da Escola Francesa da Análise do Discurso, por ter sido através da leitura de um de seus textos (2002) que surgiu a idéia de desenvolver o presente trabalho, como explicito mais adiante. 
O autor faz uma comparação entre o texto publicitário e o jornalístico e defende a idéia de que, para o primeiro, existe uma maior necessidade de elementos de preservação da face pelo fato de que ele não é deliberadamente comprado, mas vem acompanhando o texto jornalístico, este sim escolhido por opção pessoal de cada leitor. Como ele mesmo afirma, o texto publicitário "pede" para ser lido, e este fato pode acarretar prejuízo para a face de ambos os interlocutores: autor e leitor do texto.

A partir dessa constatação, redireciono meus estudos para o contexto educacional, observando que pode haver uma relação entre o texto publicitário e o texto de um livro didático. Minha reflexão parte do pressuposto de que, apesar de cada um deles pertencer a um contexto distinto e realizar papéis diferenciados, ambos têm em comum a característica de serem leituras impostas. No caso do livro didático, não é o aluno quem o escolhe. Em muitas ocasiões, também não é o professor, mas a instituição de ensino, ou mesmo alguma instância superior. Sendo assim, da mesma forma que o texto publicitário, sob a perspectiva de Maingueneau (2002), o texto do livro didático apresenta-se como uma possibilidade de ameaça às faces do autor e do leitor, cada um com seu papel definido na interação.

Meu objetivo, no presente trabalho, portanto, é investigar como o autor de um livro didático elabora o seu discurso em relação ao uso de estratégias que possam atenuar possíveis ameaças às faces dos interlocutores, a partir da observação das formas lingüísticas usadas para realizar atos de fala que sejam potencialmente ameaçadores da face. Sem ter a pretensão de responder a essa pergunta de uma forma ampla, dada a infinidade de exemplares de livros didáticos que podem configurar um corpus para este tipo de estudo, busco apenas iniciar um processo de observação e análise interpretativa de uma amostra do texto em questão, a partir do pressuposto de que a sua leitura, realizada de forma imposta, pode fazer com que o seu autor use artifícios lingüísticos para amenizar tal imposição. 
O livro selecionado para análise foi selecionado da coleção New Password: English, de Amadeu Marques (2000), devido ao fato de a mesma ter sido recentemente enviada pela editora para apreciação e possível adoção em sala de aula na escola onde leciono, o Centro Federal de Educação Tecnológica de Alagoas - CEFET/AL. A referida coleção é composta de três volumes. Após uma rápida e superficial leitura dos três, escolhi o segundo volume, por acreditar ser o mesmo o correspondente ao programa da segunda série do Ensino Médio, série na qual leciono atualmente. O corpus foi constituído de duas partes iniciais do livro: o texto de apresentação e a primeira unidade. Vale ressaltar que o texto de apresentação é o mesmo nos três volumes da coleção.

\section{Uma breve introdução à Teoria das Faces}

Erving Goffman (1967), em sua teoria das faces, pressupõe que em todo encontro social as pessoas têm uma necessidade natural de passar para os outros uma imagem pessoal favorável delas mesmas, de acordo com seus próprios conceitos do que é socialmente mais ou menos aceitável, e fazem isso através de estratégias verbais e/ou não verbais, de acordo com a situação que se apresenta. O termo original inglês face refere-se, assim, à imagem social do indivíduo².

Brown \& Levinson aprofundam o estudo de Goffman, trabalhando especificamente com atos de fala e a polidez. Em sua obra Politeness: some universals in language usage (1987), listam uma série de atos que consideram intrinsecamente ameaçadores da face ${ }^{3}$, ou seja, que quando realizados apresentam riscos para a imagem social dos interlocutores. Alguns exemplos são os atos de desculpar-se, dar ou receber uma ordem, receber ou fazer uma solicitação, etc.

Através de um estudo detalhado de três diferentes línguas e suas respectivas culturas, os autores apresentam uma série de estratégias que podem ser usadas pelos atores sociais para atenuar a ameaça destes atos.
${ }^{2}$ Doravante, podemos empregar, visando um mesmo sentido, os termos face ou imagem. ${ }^{3}$ Originalmente, Face Threatening Acts (FTAS). 
${ }^{4}$ Já referido aqui na citação de Maingueneau (2002; p. 40).

${ }^{5}$ Neste trabalho, por focalizarmos a escrita, não usaremos as expressões falante e ouvinte, mas, respectivamente, autor e leitor.

${ }^{6}$ Para estas denominações, os autores usam respectivamente os termos on recorde off record. (1987: 68-9)
Propõem que a face tem dois aspectos diferenciados que denominam de face positiva e face negativat. O primeiro, a face positiva, é o desejo que as pessoas têm de mostrar uma imagem social aceita e aprovada pelos outros. E o segundo aspecto, a face negativa, é a necessidade de preservação do próprio espaço, da privacidade e intimidade de cada um, que nem sempre se quer compartilhar com os outros. A dualidade positivo e negativo nesse contexto não tem uma conotação de oposição de valores. Como nos esclarece Yule: "a palavra 'negativo' aqui não tem sentido de algo 'ruim', mas é apenas o pólo oposto de 'positivo'” (1996: 61-2), ou seja, são apenas termos que se opõem em relação aos desejos dos indivíduos em razão do que se quer expor (face positiva) e do que se quer preservar (face negativa).

As ameaças à face podem variar, de acordo com a natureza de cada ato, focalizando, diversamente, as faces positiva e/ou negativa do falante e/ou do ouvinte. Assim, por exemplo, expressões de desaprovação, crítica, insulto ou acusações são vistas como ameaçadores da face positiva do ouvinte, enquanto atos impositivos como, por exemplo, ordens, requerimentos, sugestões e recomendações são ameaçadores da face negativa do ouvinte. Por outro lado, os atos que expressam pedidos de desculpa, confissões, admissões de culpa ou de responsabilidade são vistos pelos autores como ameaçadores da face positiva do falante, ao passo que aceitar pedidos de desculpas pode ameaçar a face negativa do falante. ${ }^{5}$ É justamente para atenuar a ameaça contida nestes e em outros atos que os interlocutores utilizam-se de estratégias discursivas denominadas estratégias de negociação da imagem. Para Brown \& Levinson (1987), essas estratégias podem ser realizadas de forma direta ou indireta ${ }^{6}$, ou seja, explícita ou implicitamente. Os autores listam uma série de estratégias verbais e as organizam em quadros explicativos (p. 102 e 131).

De acordo com tais estratégias de negociação da face, apresentarei a seguir as duas partes do livro que nos propomos a analisar: a apresentação e a primeira unidade. 


\section{Parte 1: A apresentação}

Segundo Brown \& Levinson (1987), o ato de apresentar-se pode constituir uma ameaça à face positiva do falante, que fica sujeito a não causar uma boa impressão inicial de si próprio, assim como à face negativa do ouvinte, que pode achar tal ato uma invasão à sua privacidade e ao seu direito de não estar disposto a conhecer algo ou alguém naquele determinado momento, implicando um futuro, e nem sempre desejado, comprometimento.

No texto de apresentação do livro (p. 3), o autor faz uso de alguns atenuantes para diminuir os possíveis riscos da situação. Inicia explicando o significado do título e o objetivo da coleção, demonstrando logo uma preocupação com a própria face positiva, quando apresenta uma renovação em sua proposta, uma modernização de seus conteúdos para acompanhar o jovem aluno de ensino médio, e um desbloqueio para a sua entrada no "universo" da língua estrangeira: "O objetivo desta coleção, agora inteiramente reformulada”, é mesmo abrir passagem para o universo da língua inglesa".

Em seguida, com a afirmação "Sabendo inglês, você deixa de ser apenas um cidadão: passa a ser um cidadão do mundo", o autor, a princípio, expõe a face positiva do leitor, ao pressupor que ele não conhece a língua alvo e que por isso ele é apenas um cidadão. Mais adiante, porém, o autor parece recuperar a imagem positiva do leitor, quando deixa implícito que ele já possui alguma habilidade com a língua inglesa e com a leitura de textos, no seguinte trecho: "Com ele você irá desenvolver seu conhecimento da língua inglesa, principalmente sua capacidade de compreender textos escritos." O autor segue preservando sua própria face positiva, ao mostrar que conhece os desejos do leitor em relação ao seu futuro e que tem consideração por eles: "Além de ser requisito essencial para os exames vestibulares, a compreensão de textos em inglês vai facilitar seus estudos universitários e ampliar suas oportunidades no campo profissional'.

Neste texto de apresentação, o autor "faz promessas", oferecendo um crescimento intelectual ao
${ }^{7}$ Nas citações dos dados, usarei sempre a fonte em itálico para grifar os trechos que estiverem sendo comentados. 
leitor em troca de sua aceitação e, conseqüentemente, de sua leitura. O ato de fazer promessas traz riscos a ambos os interlocutores, sendo uma ameaça à face positiva do autor, que pode não corresponder às expectativas do outro, e à face negativa do leitor, que pode se sentir pressionado a aceitar tal ato e, portanto, em débito para com o primeiro (BROWN \& LEVINSON, 1987). Para atenuar estas ameaças, o autor pronominaliza em terceira pessoa o livro que ele próprio escreve, afastando dele próprio o compromisso de realizar o que está sendo prometido: "New Password: English dá clara prioridade à leitura: apresenta textos de diversos estilos [...] Aborda uma grande diversidade de temas [...] Assim, contribui para a sua formação cultural e, principalmente, para a formação de sua cidadania." Distanciando o seu objeto - o livro dele mesmo, o autor atenua um possível comprometimento pessoal entre ele e o seu leitor. Neste caso, a impessoalidade é uma estratégia adequada para salvaguardar ambas as faces envolvidas na interação.

\section{Parte 2: A primeira unidade}

A primeira unidade compõe, junto com outras três unidades, a primeira parte do volume, intitulada Our place in the universe (p. 7). Ao iniciar usando o pronome referente à primeira pessoa do plural our, o autor já se inclui no texto, apresentando logo pontos em comum e assegurando identificação com o leitor. A gravura escolhida para ilustrar essa página acompanha bem a idéia de cooperação, ao mostrar duas alunas trabalhando juntas em um aparelho de computador. São jovens, como se supõe ser o leitor.

A Unidade 1 (p. 9) é apresentada com o título So Many Suns, So Many Worlds - que também é o título do texto para leitura à página posterior - e um texto explicativo em português. Esse texto o autor já inicia com uma estratégia que preserva sua própria face positiva, ao usar o nome de alguém reconhecido e aceito socialmente na esfera intelectual do mundo ocidental, o cientista Carl 
Sagan, ao tempo em que valoriza o gosto do leitor, oferecendo-lhe algo original e de recente publicação: "O texto a seguir é um trecho não adaptado de Billions and Billions, o último livro de Carl Sagan, cientista norteamericano falecido em 1977.". Em seguida, o autor continua demonstrando cooperação e identificação com o leitor, incluindo-se no texto junto com ele: "Sagan [...] ajudou-nos, com sua obra, a entender melhor o nosso lugar no universo". Ao final deste texto introdutório à Unidade 1 , o autor parece preocupar-se em preservar a face negativa do leitor, ao fazer uma pergunta oferecendo dados e sugerindo uma possibilidade e uma suposta habilidade do leitor, sem ser explicitamente impositivo "Baseando-se na ilustração e no título, que hipótese você pode formular sobre o assunto do texto?". Com este questionamento, o autor sugere uma formulação prévia da atividade que vai ser iniciada em seguida, facilitando a sua execução e, assim, parecendo demonstrar, mais uma vez, um intuito de cooperar com o aluno-leitor.

Na próxima página (p. 10), temos o referido texto de Carl Sagan, e, em seguida, a seção Explore some more, em que o autor apresenta uma série de sugestões para complementação à leitura do tema, inclusive através de outros canais de comunicação, como o cinema e a TV. Com essa contribuição, o autor preserva a sua face positiva e a do leitor, demonstrando que é possuidor de um maior conhecimento sobre o assunto e que deseja compartilhar e, assim, cooperar com o leitor, para que o mesmo possa também expandir seus conhecimentos.

A seguir, há uma fotografia colorida de Carl Sagan (p. 11) e um texto em língua inglesa que o apresenta. $O$ autor continua preservando sua própria face positiva, agora comprovando para o leitor que o texto oferecido para leitura é de alguém reconhecidamente importante, através da citação de cargos e títulos do cientista e de vários de seus feitos, no âmbito da ciência, e através também da própria fotografia, que mostra o cientista falando em um microfone, e parece estar proferindo uma palestra ou dando uma entrevista. Seguindo esta mesma linha, ao final 
da unidade, há mais dois textos para leitura (p. 20-1), cujos autores são o historiador americano Carl Becker e o físico alemão Albert Einstein.

Nos enunciados das atividades, o autor mantém um discurso claro e objetivo, explicitando diretamente o que deseja do aluno, com os habituais imperativos: identifique, complete, observe, leia, faça, relacione, procure, etc. Os enunciados escritos em língua inglesa seguem o mesmo estilo: "Read the questions, give the answers [...] and find the password." Em alguns, um pequeno texto informativo precede o comando, como no exemplo a seguir: "This is the planet where we live. We must take good care of it. What planet is this? Write the second letter of its name." $\mathrm{Na}$ estrutura de todos os enunciados da unidade, não observamos nenhum termo que consideramos atenuante do ato diretivo. Em apenas um deles, uma expressão de função explicativa: "Em cada série de palavras, 'denuncie o intruso', isto é, identifique as palavras que não pertencem à coluna em que se encontram" (p. 12). Segundo Brown \& Levinson (1987), dar explicações faz parte das estratégias da polidez positiva, em que o autor demonstra interesse em auxiliar o leitor, que, neste caso, pode necessitar de uma informação mais clara para realizar a ação esperada.

O uso dos verbos no imperativo (de forma marcante nos enunciados dos exercícios) e de outras expressões taxativas, sem qualquer elemento atenuante, pode ser compreendido como um reflexo do estilo autoritário do autor, que, em sua maioria, não leva o aluno a posicionamentos críticos, mas a respostas prontas, esperadas como corretas. Esta é uma questão que não abordamos diretamente em nosso trabalho, mas que entendemos ser fundamental, quando se fazem reflexões sobre as interações no contexto da sala de aula, pois concordamos com Zozzoli (2002), em suas considerações a respeito da qualidade dos trabalhos que favorecem uma resposta ativa do aluno como leitor e produtor de textos.

Nas páginas intermediárias da Unidade 1, observando a inclusão, entre um exercício e outro, ou até 
fazendo parte dos mesmos, de gravuras como cartoons e fotos de ídolos do cinema americano, e entendemos ser este um recurso usado pelo autor para estimular o alunoleitor a apreciar o material didático. Neste caso, parece que o autor preocupa-se em oferecer elementos pictóricos e imagens de pessoas com os quais o leitor possa se identificar, atentando, assim, para a valorização de fatores afetivos que acreditamos, em conformidade com Krashen (1982), ser um aspecto bastante relevante para o desenvolvimento do processo de ensino e aprendizagem.

Em relação aos breves textos em que o autor explica algum ponto gramatical ou estratégia de leitura, verificamos que há apenas o uso eventual do discurso na $1^{\text {a }}$ pessoa do plural, como nos seguintes trechos: "Em textos de caráter científico como "So Many Suns, So Many Worlds", é comum encontrarmosmuitas palavras cognatas [...]" (p. 11), e "Pelo contexto podemos concluir [...]" (p. 18). Este recurso, que assevera reflexividade e faz parte também da polidez positiva, repete-se mais algumas vezes no texto que encerra a unidade: "Que outras lições pode nos dar a inimaginável vastidão do universo? Você acha, por exemplo, que só pode existir vida inteligente no nosso planeta?" (p. 22). Esse último texto compõe uma atividade que objetiva levar o aluno a refletir sobre o tema que foi visto. O autor solicita ao aluno que ele se questione sobre as opiniões dos cientistas citados e dê a sua própria opinião: "Você concorda com eles?". Em outros dois trechos, o autor continua solicitando a opinião pessoal do aluno: "Você acha, por exemplo, que só pode existir vida inteligente no nosso planeta?" e "Você acha que o ser humano ainda tem motivos para ser arrogante?". Solicitar a opinião do outro é considerar os desejos de sua face positiva, pois, dessa forma, o autor dá atenção e demonstra interesse pelas idéias e valores do seu interlocutor. Por outro lado, é interessante observar que, em um destes trechos em que o autor poderia ter repetido o discurso em $1^{\text {a }}$ pessoa do plural (como referido no parágrafo anterior), ele prefere usar a $3^{a}$ pessoa do singular, pois, neste caso, ele está livrando tanto a sua imagem como a 
do leitor de um conceito geralmente mal visto pela sociedade, que é a arrogância: "Você acha que o ser humanoainda tem motivos para ser arrogante?".

Através de expressões recorrentes em toda a unidade, como, por exemplo: "Juntamente com um colega, identifique..." (p. 11); "Em dupla, relacione..." (p. 16); "Juntamente com um colega, relacione..." (p. 17); "Trabalhando em dupla, procure..." (p. 17); "pergunte a um colega a opinião dele..." (p. 19). Vemos uma constante preocupação do autor em sugerir trabalhos em conjunto, demonstrando atentar para a cooperação na negociação, refletida explicitamente no modo como propõe a realização das atividades.

\section{Uma analogia entre a lição no livro e a aula na sala}

Após analisar os textos do livro didático em questão, sob a perspectiva do uso de estratégias discursivas de negociação da face como um elemento de interação entre autor e leitor, levantamos alguns pontos para considerações e questionamentos.

Em primeiro lugar, observamos que, neste objeto estudado, que é apenas um exemplar entre tantos outros, os recursos verbais e não verbais de preservação da imagem estão presentes, e são recorrentes em trechos bem significativos. As estratégias que encontramos, no texto analisado, mostram que há uma preocupação freqüente por parte do autor com a sua própria face e, conseqüentemente, também com a do leitor. Essas estratégias, no entanto, estão mais presentes nas partes iniciais e finais da lição, nos textos introdutórios e no texto que encerra a unidade. Nessas ocasiões, o autor dirige-se ao leitor de uma forma mais pessoal, fazendo sempre uso de atenuantes lingüísticos. Essa oferta pode gerar uma contra resposta semelhante, segundo o princípio da cooperação postulado por Grice (apud'l'avares, 2001), que diz que um processo de comunicação implica um acordo tácito entre os seus participantes, levando-os a 
respeitar regras, como em um jogo, que variam de acordo com o contexto e o papel de cada um.

No livro didático, o papel do autor é fazer com que o seu leitor realize tarefas para atingir um determinado aprendizado prometido pelo primeiro. Para atingir esse objetivo, ele colabora com o seu interlocutor com um discurso que o valoriza. Sentindo-se valorizado, o alunoleitor pode mais facilmente aceitar as imposições de seu interlocutor e participar do processo comunicativo que ali se instaura. Por outro lado, não podemos deixar de considerar que essa constante ação do autor, que pode ser interpretada como uma preocupação recorrente em cooperar com o outro, pode ser vista também pelo ângulo da imposição camuflada, já que, a princípio, o texto do livro didático é considerado aqui, assim como o texto do informe publicitário, como uma leitura imposta. No caso do texto de publicidade, pressupõe-se que o leitor comum não está realmente obrigado a ler, pois supõe-se que seja o texto jornalístico que de fato o interessa. O texto do livro didático, porém, pela própria assimetria de papéis de professor e aluno em sala de aula, pode ser realmente veiculado como uma imposição de leitura.

O fato de as estratégias de preservação da face encontrarem-se mais presentes em determinadas partes do que em outras, levou-nos a outra reflexão. Percebemos que, como em uma unidade de aula que segue princípios metodológicos da abordagem comunicativa, as atenções dadas ao início e ao final da unidade parecem semelhantes em ambos os contextos. É comum entre os professores a preocupação com a forma de apresentar o novo insumo ao aluno, para que ele possa, desde os primeiros momentos, interessar-se pela atividade de aula, para com isso se obter a participação desejada e, talvez, uma aprendizagem bem sucedida. As chamadas atividades de warm-up fazem bem esse papel. Às vezes, atividades realizadas em cinco minutos já inserem o aluno no universo do tema da aula.

No caso específico da leitura, temos as conhecidas pre-reading activities, ou atividades de predição de leitura, que têm como objetivo principal ativar o conhecimento 
anterior do aluno-leitor em relação ao tópico que vai ser apresentado no texto (DIAS, 1990). Dessa forma, são atenuadas as incertezas do aluno em relação ao que será lido, fazendo com que ele se sinta mais confortável emocionalmente e mais preparado cognitivamente para a apresentação de um novo insumo. A hipótese do filtro afetivo (KRASHEN, 1982), que estabelece como os fatores afetivos se relacionam com o processo de ensino e aprendizagem de uma língua estrangeira, confirma a importância desse tipo de atividade na aula de LE:

A atividade final, que visa à avaliação do alunoleitor sobre o que foi apresentado, seja no texto do livro didático ou em toda a unidade de aula, é também bastante relevante. A realização deste tipo de atividade permite ao aluno o exercício da crítica, aceitando ou refutando a informação que lhe foi veiculada. Segundo Almeida Filho (1993), em uma aula de língua estrangeira, esta é a fase em que o aluno "retorna a um nível de consciência e realidade que o engajamento anterior em atividades de uso permitira esquecer ou abrandar" (1993, p. 31). No entanto, em concordância com esse mesmo autor, considerando a relevância de todos os momentos da aula, e de quanto os fatores do "estrangeirismo" da língua-alvo podem deixar o aluno desconfortável e até mesmo resistente ao processo de aprendizagem, acreditamos que as atitudes de motivação e minimização destas diferenças não devem ser adotadas apenas nos momentos iniciais e finais da unidade, mas ao longo de toda a aula.

\section{Conclusão}

Despertar a atenção do outro, apresentar-se bem, manter a atenção e despedir-se, sentindo que causou uma boa impressão, ou, pelo menos, alguma impressão, no outro, é algo desejado pelas pessoas em várias situações. Nem sempre obtemos êxito, nem sempre conseguimos causar uma "boa imagem" de nós mesmos, e isso pode se tornar ainda mais difícil quando nossa presença é, de alguma forma, imposta ao outro. O que nos impulsionou a realizar a 
presente análise foi justamente a identificação desta problemática na leitura de um livro didático, e, após analisar as escolhas lingüísticas do autor em relação à negociação das imagens em jogo, as nossas reflexões nos levaram a fazer uma relação do objeto estudado com o contexto no qual ele está inserido, a sala de aula.

Seja como autor de um livro didático, seja como professor na sala de aula, o fato de "ser" uma imposição pode fazer com que sejam adotadas posturas diversas, refletidas nas escolhas lingüísticas de cada um: pode-se usar o autoritarismo, que a própria posição confere naquela ocasião, ou pode-se tentar negociar a própria imagem de forma menos impositiva, mostrando que há preocupação e desejo de cooperação com o outro.

Como professora de ensino médio, convivendo diariamente com alunos-leitores em sala de aula, acredito que posso compreender melhor, e contribuir mais efetivamente com o processo no qual estou envolvida, quando procuro estar sempre atenta às diversas possibilidades de interpretação das atuações lingüísticas das pessoas em seus diferenciados, e não raro assimétricos, papéis sociais. A partir da realização adequada de atividades que, além de apresentarem um bom insumo, favorecem a cognição e a afetividade através da ativação de um conhecimento anterior do aluno-leitor, e o exercício do seu senso crítico através da sua própria avaliação do que lhe foi apresentado, creio que é possível proporcionar ao mesmo a possibilidade de construir o seu próprio saber com uma postura mais segura e independente, fundamental para o seu crescimento pessoal.

Para finalizar este artigo, após todas essas reflexões, cito Morin, com quem concordo, quando afirma que "a missão do didatismo é, antes de tudo, encorajar o autodidatismo, despertando, provocando, favorecendo a autonomia do espírito" (2001; p. 11), e nos lembra, mais adiante, que essa postura "de encorajar, de instigar a aptidão interrogativa e orientá-la para os problemas fundamentais de nossa própria condição e de nossa época" não pode ser inserida em um programa curricular, 
mas ser impulsionada pelo que o autor denomina de "fervor educativo" (2001; p. 22). Acredito que só através deste sentimento torna-se possível proporcionar aos alunos-leitores oportunidades para que eles cresçam, vendo e compreendendo o mundo em que estão inseridos com seus próprios olhos, e assim compreendermos que eles também nos proporcionam crescimento com suas próprias vivências para, juntos, com liberdade e independência de idéias, dentro das relativas possibilidades de autonomia que nos são conferidas (ZOZZOI.I, 2002), seguirmos em frente, no contínuo processo de construção do nosso próprio saber. 


\section{Referências}

ALMEIDA FILHO, J.C. Dimensões comunicativas no ensino de línguas. Campinas, SP: Pontes, 1993.

BROWN P.; LEVINSON, S. C. Politeness: some universals in language usage. Cambridge: CUP: 1987.

DIAS, R. Inglês instrumental. Leitura crítica: uma abordagem construtivista. Belo Horizonte: UFMG, 1990.

GAMA. M.C.M. Estratégias de preservação da imagem em sala de aula de língua estrangeira. Monografia de conclusão do Curso de Especialização em Ensino/Aprendizagem de Línguas Estrangeiras pela Universidade Federal de Alagoas, 1996.

. O fenômeno da preservação da face em interações orais do tipo entrevistas jornalísticas de televisão. Dissertação de Mestrado do Programa de Pós-Graduação em Letras e Lingüística pela Universidade Federal de Alagoas, 1999.

GOFFMAN. E. Interaction ritual. U.S.A.: Doubleday \& Company, 1967.

KRASHEN, S. D. Principles and practice in second language aquisition. Oxford: OUP, 1987.

MAIngufneAu, D. Análise de textos de comunicação. 2 ed. São Paulo: Cortez, 2002.

MARQUeS, A. New password: English. Vol. 2. 10 ed. São Paulo: Ática, 2000.

MORIN, E. A cabeça bem-feita:repensar a reforma, reformar o pensamento. 5 ed. Rio de Janeiro: Bertrand Brazil, 2001.

TAVARES, R. R. A negociação da imagem em sala de aula de língua inglesa. Tese de Doutorado do Programa de PósGraduação em Lingüística pela Universidade Federal de Pernambuco, 2001.

WIDDOWSON, H.G. Oensino de línguas para a comunicação. Tradução J. Carlos P. Almeida Filho. Campinas, SP: Pontes, 1991.

YULE, G. Pragmatics. Oxford: Oxford University Press, 1996.

ZOZZOLI, R. M. D. Compreensão e produção responsivas ativas: indícios nas produções dos alunos. In.: ZOZZOL.I, R. M. D. (org). Ler e produzir: discurso, texto e formação do sujeito leitor/produtor. Maceió: EDUFAL, 2002. 